\title{
INTER-RELAÇÕES ENTRE O ENSINO, A PESQUISA E A EXTENSÃO EM ARQUITETURA E URBANISMO A PARTIR DOS TRABALHOS DESENVOLVIDOS PELO NAU - NÚCLEO DE PROJETOS ARQUITETÔNICOS E URBANOS DA UNESP
}

\author{
Evandro Fiorin \\ UNESP-Campus de Presidente Prudente / PROEX-UNESP / FUNDUNESP.
}

\section{RESUMO}

Neste artigo buscamos apresentar a experiência que está sendo realizada em um núcleo de projetos de arquitetura e urbanismo, que desenvolve trabalhos voltados à comunidade em geral, junto à universidade pública, ao longo dos últimos três anos. Nele discutimos a organização e o funcionamento do NAU - Núcleo de Projetos Arquitetônicos e Urbanos da UNESP-Campus de Presidente Prudente e como acreditamos que as inter-relações entre o ensino, a pesquisa e a extensão em arquitetura e urbanismo podem ser instigadas pela mútua participação de docentes e discentes, na realização de projetos em várias escalas de intervenção, no âmbito da universidade, da sociedade civil e em concursos de ideias, exatamente, porque, o grau de aproximação com a realidade pode ser mais tangível, na medida em que as demandas reais solicitam posicionamento político, pesquisa acurada e uma resposta crítica, acompanhadas de um desenho responsável.

Palavras -chave: Projeto, Arquitetura, Ensino, Pesquisa, Extensão.

\section{INTRODUÇÃO E OBJETIVO}

O NAU - Núcleo de Projetos Arquitetônicos e Urbanos da FCT - Faculdade de Ciências e Tecnologia da UNESP - Universidade Estadual Paulista, Campus Presidente Prudente, localizado na unidade Núcleo Morumbi, colabora para consolidar o curso de Arquitetura e Urbanismo, reforçando sua inserção social e comunitária, uma vez que sua produção se orienta para a realização de projetos voltados a instituições municipais, estaduais, entidades civis e religiosas, autarquias, fundações, organizações, sem fins lucrativos, comunidades e prefeituras municipais da região do Oeste Paulista, com a finalidade de aprimorar a qualidade de vida da população.

Com seu viés extensionista o aluno da graduação tem a possibilidade de exercitar a futura profissão em um espaço que permite aos docentes e discentes, bolsistas e voluntários, serem, sobretudo parceiros no desenvolvimento de pesquisas e da concepção projetual. Deste modo, busca desmistificar a aprendizagem de projeto de arquitetura e urbanismo, diante da dicotomia existente entre: o que ensina e o que aprende; pois estimula e tem como pressuposto uma maior troca de experiências, já que o aluno da graduação que participa de quaisquer das atividades projetuais, deixa de ser um mero aprendiz, para se tornar um agente importante, pois adquire responsabilidades. 
Ao desenvolver um projeto de arquitetura e urbanismo que tem como finalidade colaborar com a melhoria da qualidade de vida das pessoas, esse aluno pode ter contato com quem irá habitar o espaço do seu projeto e: participa de algumas das suas mazelas sociais, em determinados casos - o que o torna a atividade de ensino-aprendizagem mais politizada; é cobrado a buscar alternativas que sejam de baixo custo, o que fomenta uma pesquisa mais acurada do que será desenvolvido, chegando a criticar modelos convencionados; e o mais importante, fazendo da prática de projeto uma atividade que suplanta o desenho hipotético da sala de aula-atelier, ao assumir as responsabilidades sobre as decisões que o arquiteto toma nessa prancheta em contato com a coletividade.

Devemos destacar, que esse processo de trabalho considera o perfil do professor de projeto de arquitetura não mais como o projetista de escritório, que faz da sala de aula um braço de sua prática profissional; nem daquele perfil de docente politicamente engajado que sobrepõe o tempo da pesquisa ao do projeto, mas cujo resultado nunca sai do papel. O "novo professor" é, sobretudo, um pesquisador-educador e seu local de trabalho é junto dos laboratórios, dos grupos de pesquisa, dos escritórios-modelo e dos núcleos de extensão, o que possibilita garantir um retorno à comunidade do conhecimento que se produz na Universidade (VELOSO; ELALI, 2003, p. 100).

Os atendimentos das diferentes entidades da sociedade civil são efetivados por meio de parcerias, convênios e termos de compromisso, no entanto, buscamos também a participação em concursos nacionais e internacionais de ideias de arquitetura e urbanismo, tendo em vista a possibilidade de estender a um número cada vez maior de pessoas a oportunidade de ter acesso à melhoria da qualidade de vida, através do fomento a projetos de arquitetura e urbanismo que primem pela postura político-crítica em relação às nossas cidades.

Da mesma forma, também buscamos participar de exposições e congressos científicos, com a publicação dos trabalhos de acordo com as políticas editoriais de modo a difundir um pensamento de pesquisa voltado à prática do projeto de arquitetura em urbanismo. Mediante os resultados obtidos até o momento, tais como menções honrosas, premiações e divulgações na mídia especializada impressa e digital dos nossos trabalhos acreditamos que estejamos construindo algumas inter-relações entre o ensino, a pesquisa e a extensão em arquitetura e urbanismo e contribuído para a geração de novas ideias.

Nesse sentido, o NAU - Núcleo de Projetos Arquitetônicos e Urbanos tem por objetivo desenvolver projetos de edificações ou de intervenções urbanas para segmentos sociais diversos e busca, a partir de suas elaborações articular e integrar docentes (responsáveis pelo referido 
projeto de extensão e colaboradores) e discentes (bolsistas e voluntários), de maneira que seu espaço se transforme em uma espécie de atelier-experimental, voltado ao ensino-aprendizagem de projeto de arquitetura e urbanismo, à pesquisa de novas tecnologias e soluções, ao necessário engajamento da universidade em atividades voltadas à comunidade, com ideais sempre articulados à prática da atuação profissional do arquiteto urbanista.

\section{MÉTODOLOGIA}

Além da manutenção, organização e funcionamento do espaço físico, cinco dias por semana, as atividades do NAU - Núcleo de Projetos Arquitetônicos e Urbanos giram em torno do feitio de projetos de arquitetura e urbanismo em fluxo contínuo. Apesar das atividades de elaboração de projetos de arquitetura e urbanismo terem cronogramas variáveis dependendo da demanda, temos como prerrogativa o desenvolvimento de, no máximo, dois projetos por bimestre, para que não haja prejuízos nos prazos de entrega.

Estabelecidas as demandas, os docentes se engajam como articuladores de cada projeto de arquitetura e urbanismo, sem que detenham o controle sobre os mesmos. Nesse caso, a participação dos alunos que recebem bolsa da universidade passa a ser colaborativa, em uma série de ações. Em alguns casos, estes podem desenvolver projetos complexos debatendo questões conjuntamente, fazendo surgir soluções que são experimentais. O método empírico é bastante utilizado nesse caso, mas não prescinde da verificação de sua validade diante das referências arquitetônicas e urbanísticas consolidadas. Nessa proposição, primamos sempre pelas respostas criativas e críticas ao status quo, desde que bem fundamentadas.

Assim, os bolsistas do NAU - Núcleo de Projetos Arquitetônicos e Urbanos desenvolvem as atividades projetuais em conjunto com os seus docentes, tornando a prática do ensinoaprendizagem em arquitetura e urbanismo des-hierarquizada, realizando levantamentos e pesquisas necessárias à elaboração de cada proposta, atendendo a comunidade em geral e organizando os grupos de trabalho envolvendo discentes voluntários. São também responsáveis pelo funcionamento permanente do espaço físico, abrindo-o ao público, recebendo e respondendo mensagens e telefonemas, organizando as pastas, material de desenho e as entradas e saídas de projetos de arquitetura e urbanismo.

\section{RESULTADOS}

Na qualidade de projeto de extensão financiado pela Pró-Reitoria de Extensão da UNESP o NAU - Núcleo de Projetos Arquitetônicos e Urbanos é atuante desde a sua criação, em 2007. No 
entanto, podemos dizer que a prática desse processo de inter-relação entre o ensino a pesquisa e a extensão se intensificou a partir do segundo semestre de 2010. Nesse caso, apresentaremos as práticas mais importantes dos últimos anos três anos, que resultaram em menções honrosas, exposições, catálogos, publicações de artigos científicos e contribuições ao Campus da UNESP de Presidente Prudente.

No ano de 2010, a pedido dos dirigentes da SITRA - Saúde Integral do Trabalhador da UNESP, sob a coordenação do professor Evandro Fiorin foi desenvolvido o logotipo da entidade pelo graduando Gustavo Favaretto Martinez; também foi realizado um estudo preliminar para expansão do $\mathrm{CCl}$ - Centro de Convivência Infantil do Campus da UNESP de Presidente Prudente, com participação de vários alunos do curso de graduação em Arquitetura e Urbanismo. Além disso, foram realizados: o anteprojeto para o Museu da Cartografia do Campus da UNESP de Presidente Prudente; o anteprojeto arquitetônico, urbanístico e paisagístico para o novo bloco de salas de aulas do Discente VII do curso de Arquitetura e Urbanismo do Campus da UNESP de Presidente Prudente, que contou com a colaboração de vários docentes e discentes do referido curso de graduação"; e o envio do projeto da "Casa de Borracha de Pneu" para o Concurso de Tipologias Sustentáveis de Habitação, promovido pela CDHU - Companhia de Desenvolvimento Habitacional e Urbano do Estado de São Paulo) e IAB - Instituto de Arquitetos do Brasil, Departamento São Paulo, onde fomos contemplados com menção honrosa².
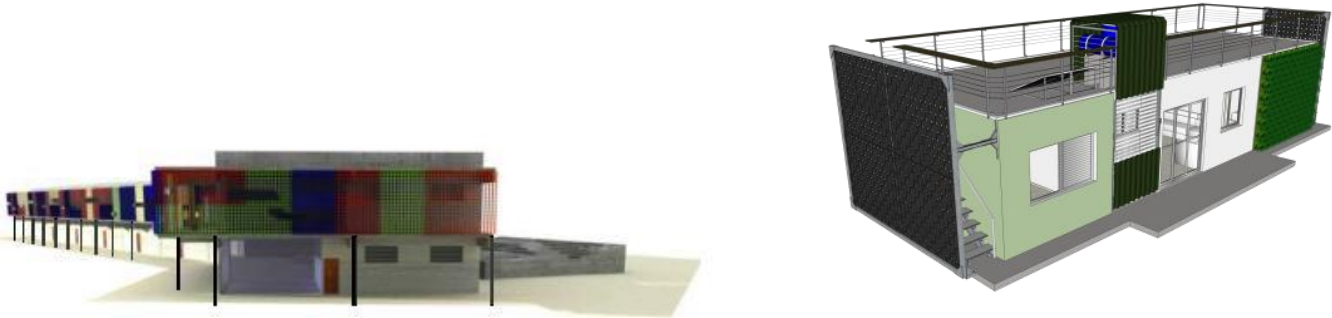

Figura 01, 02. anteprojeto do Bloco de Salas de Aula do Discente VII do Campus de UNESP de Presidente Prudente; Casa de Borracha de Pneu. Fonte: Arquivos do NAU 2010.

No ano de 2011 foram encaminhados projetos para: o 6ㅇ Prêmio de Pré-Fabricados de Concreto, promovido pela ABCP - Associação Brasileira de Cimento Portland e IAB; a $9^{\mathrm{a}}$ Bienal

\footnotetext{
${ }^{1}$ Este projeto contou com a participação dos professores: Cristina M. P. Baron, Hélio Hirao, Evandro Fiorin e Fernando Sérgio Okimoto e dos alunos de graduação em arquitetura e urbanismo: Evidio Lucas Minzone, Gustavo Favaretto Martinez, Mariana Garcia Junqueira, Marcella Silva Fratantônio, Nathália Maule Brigido e Victor Martins de Aguiar. Posteriormente este projeto foi publicado e apresentado no VI Encontro Nacional e IV Latino-Americano sobre Edificações e Comunidades Sustentáveis em Vitória, Espírito Santo e na mesma oportunidade, na Bienal de Sustentabilidade.

${ }^{2}$ Este projeto contou com a participação dos docentes Evandro Fiorin e Fernando Sérgio Okimoto e dos discentes: Suellen Ferreira da Costa, Paula Aparecida Santini de Almeida, Marina Mello Vasconcellos, Carlos Eduardo Soares de Sousa, Hiwersen Angelo Gnocchi Godoy e Victor Martins de Aguiar.
} 
Internacional de Arquitetura de São Paulo, na categoria Escolas de Arquitetura. ${ }^{3}$ Além disso, houve a participação no Concurso de Esculturas Urbanas da Tetra Pak e a proposta enviada foi selecionada, construída e exposta na Praça Victor Civita, em São Paulo ${ }^{4}$. Importante ressaltar aqui, que a concepção inicial da proposta enviada surgiu de um trabalho desenvolvido em sala de aula, sendo posteriormente melhor desenvolvido junto ao NAU. Pela sociedade civil, a OAB - Ordem dos Advogados do Brasil de Presidente Prudente nos chamou a desenvolver no Fórum de Presidente Prudente, um estudo preliminar para ampliação do estacionamento ${ }^{5}$. No Campus da FCT-UNESP foram realizados estudos preliminares para o circuito de caminhada e academia da terceira idade solicitados pela SITRA - Saúde Integral do Trabalhador da UNESP; readequação e novo layout do espaço físico das salas das seções técnicas de referência e aquisição da biblioteca e dos laboratórios do curso de Física do Campus da UNESP de Presidente Prudente; o projeto da refuncionalização da Antiga Sede da ASA - Associação dos Servidores Administrativos do Campus da UNESP de Presidente Prudente; e, em complementação ao projeto do Museu da Cartografia foi projetada uma cobertura para acesso lateral e uma escada-rampa de união do prédio Docente III com a Central de Laboratórios do Departamento de Cartografia. Para o Campus da UNESP de São José do Rio Preto apresentamos um anteprojeto para o Laboratório Interdisciplinar do curso de Pedagogia do IBILCE - Instituto de Biociências, Letras e Ciências Exatas ${ }^{6}$.
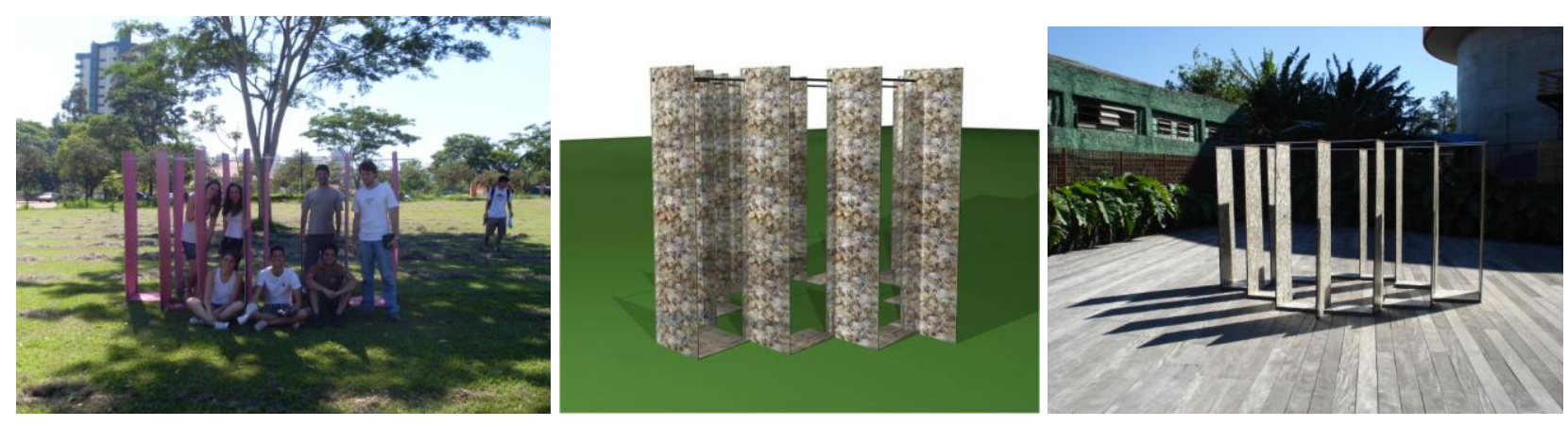

Figura 03, 04, 05. protótipo inicial da proposta para o Concurso Esculturas Urbanas da Tetra Pak em escala 1:1 desenvolvido em disciplina de projeto; maquete eletrônica da proposta enviada; escultura urbana construída e exposta na Praça Victor Civita em São Paulo; respectivamente.

Fonte: Arquivos do NAU 2011.

\footnotetext{
${ }^{3}$ No trabalho enviado para a 9a. Bienal Internacional de Arquitetura participaram os docentes: Cristina M. P. Baron, Evandro Fiorin e Arlete Maria Francisco e os discentes: Artur Felipe da Costa Rosa, Danilo da Silva Barbosa, Felipe Paulino Dubiela, Marcos Paulo Bento de Freitas, Pétilin assis de Souza

${ }^{4} \mathrm{Na}$ proposta enviada para o Concurso Esculturas Urbanas da Tetra Pak os autores do trabalho foram: Gustavo Favaretto Martinez; Bruno Celso Gobette Rodrigues; Deivis Augusto Nachif Fernandes; Marcelo Batista Pigioni, sob a orientação do Prof. Dr. Evandro Fiorin e colaboração do Prof. Dr. César Fabiano Fioriti.

${ }^{5}$ Nesse anteprojeto para ampliação do estacionamento do Fórum de Presidente Prudente trabalharam os discentes: Gustavo Favaretto Martinez; Bruno Celso Gobette Rodrigues; Deivis Augusto Nachif Fernandes; Marcelo Batista Pigioni, sob a supervisão do Prof. Dr. Evandro Fiorin e da Profa. Dra. Arlete Maria Francisco.

${ }^{6}$ Todos esses projetos para os campi citados da UNESP foram supervisionados pelo Prof. Dr. Evandro Fiorin tendo como bolsista o aluno Diego Marangoni dos Santos e, posteriormente, os alunos Alex Daniel Ribeiro Pátaro e Luiz Gustavo Chagas.
} 
No ano de 2012 podemos ressaltar a participação em um Concurso de Ideias para o Museu de Arte Contemporânea de Buenos Aires, com a finalidade de promover e estimular a inspiração e inovação na capital Argentina. Além disso, buscamos trabalhar em parceria com algumas entidades sem fins lucrativos, para as quais foram desenvolvidos projetos arquitetônicos importantes, como: o da cobertura da quadra poliesportiva para a Casa da Sopa São Francisco de Assis, em Presidente Prudente; e para a Fundação Florestal do Estado de São Paulo, o Centro de Visitantes do Parque Estadual Morro do Diabo, em Teodoro Sampaio ${ }^{7}$.
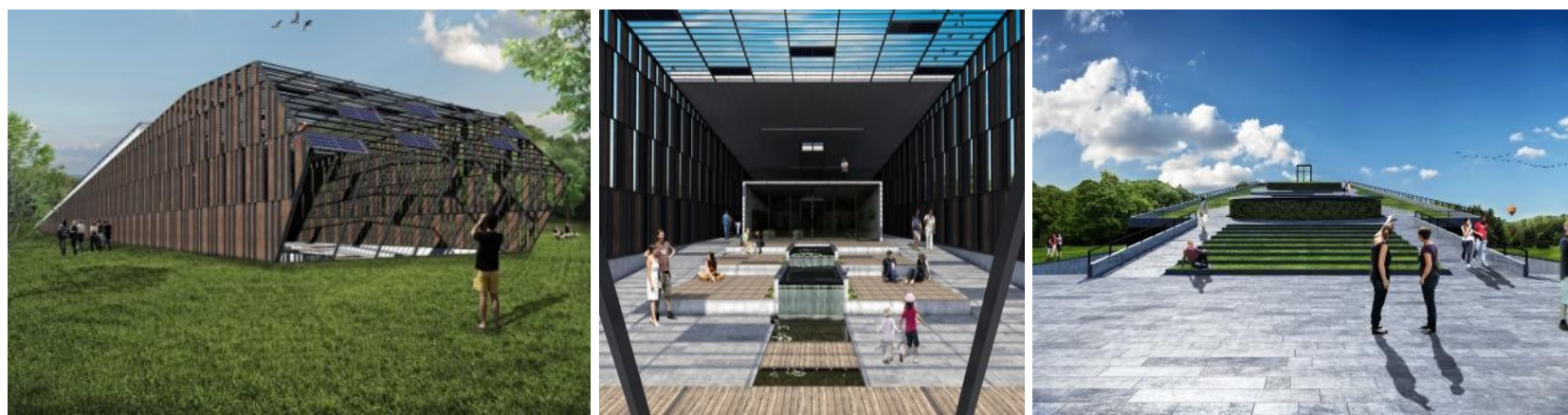

Figura 03, 04, 05. anteprojeto arquitetônico para o Centro de Visitantes do Parque Estadual Morro do Diabo em Teodoro Sampaio. Fonte Arquivos do NAU, 2012-13.

Em 2013 estamos estudamos propostas para uma Carreta Cultural, espécie de protótipo móvel que levará ações culturais aos diversos campi da universidade espalhados pelo Estado de São Paulo. Uma ideia ainda a ser apresentada à Pró-Reitoria de Extensão da UNESP. Além dessa proposta estamos trabalhando no projeto para uma nova sede da Congregação das Irmãs da Copiosa Redenção, incluindo claustro, espaço de celebrações e capela, próximo ao Instituto Brasileiro do Café, em Presidente Prudente-SP${ }^{8}$.

\section{DISCUSSÃO}

No primeiro semestre de 2013 buscamos elaborar um projeto para a nova sede do NAU Núcleo de Projetos Arquitetônicos e Urbanos, com a intenção de que este possa se localizar próximo do novo bloco de salas de aulas do curso de Arquitetura e Urbanismo no Campus da UNESP de Presidente Prudente. Com uma proposta arquitetônica que busca agasalhar a ideia de inter-relação entre o ensino, a pesquisa e a extensão, esse espaço, imaginado em exercício projetual, se constitui por áreas coletivas de trabalho entreabertas para as esplanadas do Campus

\footnotetext{
${ }^{7}$ O desenvolvimento desse projeto foi realizado mediante recursos oriundos de um outro projeto de extensão, devido sua complexidade. Teve como coordenador o Prof. Dr. Evandro Fiorin e como bolsista o aluno Diego Marangoni dos Santos. O anteprojeto foi amplamente publicado em revistas especializadas da área de arquitetura e urbanismo e apresentado em congressos ligados à questão da sustentabilidade ambiental.

${ }^{8}$ Estes projetos desenvolvidos no ano de 2013 contam com a participação dos alunos Pedro Henrique Benatti, Bruno Vinicius da Palma Novaes e Victor Martins de Aguiar, sob a coordenação do Prof. Dr. Evandro Fiorin.
} 
de Presidente Prudente, de maneira a acolher não apenas os alunos da universidade, mas também a comunidade em geral. Com essa proposição esperamos que esse laboratório seja um lugar onde os alunos possam fazer suas pesquisas em periódicos especializados e no acervo de projetos do próprio núcleo de projetos arquitetônicos, trocar informações com bolsistas, tomar contato com a comunidade atendida e, principalmente, dimensionar uma nova atmosfera para o ensino de arquitetura e urbanismo, indissociado da pesquisa e da extensão.

\section{CONSIDERAÇÕES}

A possibilidade de construir uma espaço de ação em projeto de arquitetura e urbanismo, em uma universidade pública é uma oportunidade única para o docente arquiteto e urbanista, em regime de trabalho de tempo integral e em dedicação exclusiva, exercitar o seu ofício. Além disso, a tarefa do arquiteto urbanista traz consigo como instrumentação ética, o compromisso de trabalhar em prol da comunidade, exaltando o papel social que está presente em sua profissão, na construção do ambiente humano. Nesse sentido, a oportunidade de buscar novas metodologias de ensino-aprendizagem em projeto de arquitetura e urbanismo perpassa, justamente, pelo exercício de fazer projeto. Aliar essa dimensão prática a uma ação que traz benefícios sociais reais para a sociedade civil é um anseio que passa a ser possível quando as inter-relações entre o ensino e a extensão podem existir conjuntamente. Uma condição que, quando imbuída pela motivação de se fazer novas descobertas, açambarcadas pelo espírito da pesquisa, se reverte em ganhos ainda maiores. Assim, apesar dos percalços, estamos tentando trabalhar nessa direção.

\section{REFERÊNCIAS}

AZEVEDO, D.; FIORIN, E.; OKIMOTO, F. S. Projeto usa pneus na construção de casas. Oeste Notícias, Presidente Prudente-SP, p. 1.4, 23 set. 2010.

BARON, C. P.; FIORIN, E.; FRANCISCO, A. M.; HIRAO, H. Complex-Cidade: o planejamento e o projeto urbano na proposta pedagógica e nas pesquisas do Curso de Arquitetura e Urbanismo da Faculdade de Ciências e Tecnologia da UNESP Campus de Presidente Prudente-SP. In: II Encontro da Associação Nacional de Pesquisa e Pós-graduação em Arquitetura e Urbanismo, 2012, NatalRN. II Encontro da Associação Nacional de Pesquisa e Pós-graduação em Arquitetura e Urbanismo Teorias e práticas na Arquitetura e na Cidade Contemporâneas Complexidade, Mobilidade, Memória e Sustentabilidade. Natal-RN: UFRN, 2012.

CAMPUS da UNESP de Presidente Prudente é contemplado com Academia da 3a. Idade. Blog da FCT. Disponível em: <http://blog.fct.unesp.br/blog/?p=1815>. 23 de julho de 2012.

CINDY, B.; FIORIN, E.; MARTINEZ, G. F. Alunos terão projeto exposto em SP. O Imparcial, Presidente Prudente-SP, p. 06B, 29 abr. 2011. 
COSTA, S. F.; FIORIN, E.; OKIMOTO, F. S.; ALMEIDA, P. A. S.; VASCONCELLOS, M. M.; GODOY, H. A. G.; SOUSA, C. E. S.; AGUIAR, V. M. Tipologia de Habitação de Interesse Social Sustentável. Revista Eletrônica Fórum Ambiental da Alta, v. 06, n. 01, Tupã-SP, ANAP / UNESP, 2010, p. 89-.

COSTA, S. F.; FIORIN, E.; OKIMOTO, F. S.; ALMEIDA, P. A. S.; VASCONCELLOS, M. M.; GODOY, H. A. G.; SOUSA, C. E. S.; AGUIAR, V. M. Casa de Borracha de Pneu. Revista Projetos, Vitruvius, ano 11, n. 126.2, São Paulo, jun. 2011. Disponível em: <http://www.vitruvius.com.br/revistas/read/projetos/11.126/3902?page=2>. Acesso em: 09 de agosto de 2011.

FIORIN, E.; OKIMOTO, F. S. ; HIRAO, H. ; BARON, C. P. Um projeto com a ideia de sustentabilidade: o edifício dos ateliês do curso de arquitetura e urbanismo da UNESP - Campus de Presidente Prudente-SP. In: VI Encontro Nacional e IV Encontro Latino-americano sobre edificações e comunidades sustentáveis - ELECS, 2011, Vitória-ES. VI Encontro Nacional e IV Encontro Latinoamericano sobre Edificações e Comunidades Sustentáveis. Vitória-ES : ANTAC, 2011. v. 01.

FIORIN, E.; OKIMOTO, F. S. CDHU e IAB premiam projetos de habitação popular, que serão contratados pelo Estado de São Paulo. Revista AU, São Paulo-SP, p. 14, 01 ago. 2010.

FIORIN, E.; OKIMOTO, F. S.; SOUSA, C. E. S.; GODOY, H. A. G.; VASCONCELLOS, M. M.; ALMEIDA, P. A. S.; COSTA, S. F.; AGUIAR, V. M. Casa de Borracha de Pneu/ Rubber Tire House. In: TEDESCHI, A. Sustentabilidade e Inovação na Habitação Popular: o desafio de propor modelos eficientes de moradia. São Paulo: Governo do Estado de São Paulo/ Secretaria de Estado da Habitação, 2010. FIORIN, E. Núcleo de Projetos Arquitetônicos e Urbanos. In: ARAÚJO, M. A. M. de. Catálogo dos Projetos de Extensão da UNESP. São Paulo-SP: PROEX, 2011, pp. 269.

FIORIN, E.; SANTOS, D. M. Painéis móveis definem centro de visitação no Parque Morro do Diabo, SP. Arcoweb. Disponível em: <http://www.arcoweb.com.br/noticias/paineis-moveis-definemcentro-visitacao-parque-morro-diabo-sp.html >. Acesso em 12 de agosto de 2013.

MARTINEZ, G. F.; GOBETTE, B.; FERNANDES, D.; PIGIONI, M. Frestas Urbanas. Folder da Exposição do Concurso Esculturas Urbanas (Ministério da Cultura \& Tetra Pak). São Paulo: Exposição na Praça Victor Civita, 2011.

ROSA, A. F.; FREITAS, M. P. B.; SOUZA, P. A. de.; BARBOSA, D. S. da. DUBIELA, F. P.; FRANCISCO, A. M. BARON, C. M. P.; FIORIN, E. 9․ Bienal Internacional de Arquitetura de São Paulo. Uma Língua, vários sotaques. 2011. (exposição).

SIEPLIN, P.; FIORIN, E.; OKIMOTO, F. S. Projeto da Unesp de PP é premiado em concurso. 0 Imparcial, Presidente Prudente, Presidente Prudente-SP, p. 2B, 23 set. 2010.

VELOSO, Maísa; ELALI, Gleice Azambuja. A Pós-Graduação e a Formação do (Novo) Professor de Projeto de Arquitetura. In: LARA, Fernando; MARQUES, S. (Org.). Desafios e Conquistas da Pesquisa e do Ensino de Projeto. Rio de Janeiro: EVC, 2003. P. 94-107. 